\title{
Kent Suçu ya da Kente Karşı Suç: İzmir Örneği
}

\author{
Dalya Hazar Kalonya ${ }^{1}$ \\ ORCID: 0000-0003-0075-0234
}

\author{
Zeynep Yildırım² \\ ORCID: 0000-0002-0845-2816
}

Öz

Çalışma, 'kente karşı suç' ile ne ifade edildiğini, literatürde kente karşı suçun nasıl kavramsallaştırıldı ̆̆ını ve İzmir özelinde işlenen kente karşı suçları araştırmaktadır. Son yıllarda Türkiye'de sıklıkla kullanılan 'kente karşı suç' kavramı ile 'kentsel suç' kavramı arasında, zaman zaman birbiriyle örtüşen eylemler içerseler dahi belirgin farklar vardır. Kentsel suç, kentte işlenen kapkaç, gasp, cinayet gibi kriminal suçları ifade ederken; kente karşı suç, kentsel mekâna, çevreye, kentlilere ve kentli haklarna zarar veren karar ve uygulamalarn tümünü ifade etmektedir. Bu suçlarn en büyük bölümünü ise 'imar kararlarına ră̆men' ya da 'imar kararları aracılığıyla' işlenen 'imar suçları' oluşturmaktadır. İlk durumda, imar suçları imar mevzuatına aykırı ve yasal anlamda suç sayılan eylemleri kapsarken; ikinci durumda, hukuk kuralları içerisinde, ayrıcalıkl imar hakları, imar afları, yasalarda ek maddeler vb. araçlar kullanılarak işlenen suçları kapsamaktadır. Bu bağlamda yapılan çalışma, dünyada ve Türkiye'de kent suçları hakkında yapılan tartışmaları özetlemekte ve TMMOB İzmir İl Koordinasyon Kurulu tarafından 2019'da çevrimiçi olarak yayınlanan 'İzmir Kent Suçları Haritası' üzerinden İzmir'e karşı işlenen suçları tartışmaktadır.

Anahtar Kelimeler: Kent suçu, kente karşı suç, kentli hakkı, planlama, İzmir

${ }^{1}$ Dr. Öğr. Üyesi, Pamukkale Üniversitesi, E-mail: dalyahazar@gmail.com

2 Şehir Plancısı, İzmir Büyükşehir Belediyesi, E-mail: yildirim.zeynep.b@gmail.com

idealkent @ Kent Araştırmaları Dergisi (Journal of Urban Studies)

http://idealkentdergisi.com

Geliş Tarihi Received Date: 17.12.2019 Kabul Tarihi Accepted Date: 11.07.2020 


\title{
Urban Crime or Crime Against the Urban: The Case of Izmir
}

\author{
Dalya Hazar Kalonya ${ }^{3}$ \\ ORCID: 0000-0003-0075-0234
}

\author{
Zeynep Yildirim ${ }^{4}$ \\ ORCID: 0000-0002-0845-2816
}

\begin{abstract}
The study investigates on what is expressed with the 'crime against the urban', how it is conceptualized in the literature and the crimes committed against Izmir. Although they may contain actions that overlap time to time, there are significant differences between the concept of 'crime against the urban' and the concept of 'urban crimes', which have been widely used in Turkey in recent years. Urban crimes refer to criminal crimes such as snatching, extortion and murder committed in the city; whereas the 'crime against the urban' refers to all decisions and practices that harm the urban space, environment, urban citizens and citizen rights. The biggest part of these crimes is the 'zoning crimes' that occurs despite the zoning decisions or through the zoning decisions. In the first case, the zoning crimes encompass actions that are contrary to the zoning legislation and deemed legally a crime; in the second case, crimes occur within the rules of law by privileged zoning rights, zoning amnesties, additional articles in the laws and similar tools. In this context, the study summarizes the debates about the urban crimes in the world and in Turkey and discuss the crimes against Izmir through the 'Izmir Urban Crime Map' published online in 2019 by UCTEA İzmir Provincial Coordination Committee.
\end{abstract}

Keywords: Urban crime, crime against the urban, citizen rights, planning, İzmir

\footnotetext{
${ }^{3}$ Assist. Prof. Dr., Pamukkale University, E-mail: dalyahazar@gmail.com

${ }^{4}$ City Planner, İzmir Metropolitan Municipality, E-mail: yildirim.zeynep.b@gmail.com

idealkent @ Kent Araştırmaları Dergisi (Journal of Urban Studies)

http://idealkentdergisi.com

Geliş Tarihi Received Date: 17.07.2020 Kabul Tarihi Accepted Date: 11.07.2020
} 


\section{Giriş}

Son yıllarda, ekonomik kalkınma, işsizlik ve terör kadar sağlıksız kentleşme de Türkiye'nin en önemli sorunları arasında sayılmaktadır (Karasu, 2009). Bu sorunu inceleyen sol ve yeşil politik gündemdeki çalışmalar da sıklıkla 'kent suçu' ya da 'kente karşı suç' kavramına değinmektedir. Ancak kent suçu (urban/city crime), doğrudan İngilizce çevirisinde kentte işlenen kriminal suçları ifade eden 'kentsel suç' (urban crime) kavramı ile karıştırılabilmektedir. Her coğrafya kendine ait kavram setleri ve mekanizmalar ile bilgi üretiyor olsa da bilginin dil ve kültür süzgecinden geçerken kazandığı ve kaybettiği anlamlar ile de tanımları dönüştürebilir nitelikte olduğu görülmektedir.

Kent suçlarına dair 1970'li yıllardan beri yabanc literatürde ve 1990'lı yıllardan beri eski Ankara Büyükşehir Belediye Başkanı Murat Karayalçın'ın tanımlaması ve Prof. Dr. İhan Tekeli'nin kavramsallaştırması ardından Türkçe literatürde yapılan çalışmalar, özellikle imar suçlarını merkezine almaktadır. Makaleler, paneller, İstanbul ve Bursa'dan sonra İzmir'de yayınlanan 'kent suçları haritası' ', kent suçları günlüğü, İstanbul kent mücadele arşivi vb. çeşitli internet siteleri ve blog yazıları, basında çıkan haberler ve eylemler ile konuya dair kamuoyu farkındalığı arttırılmaya çalışılmaktadır.

Günümüzde Türkiye'de daha sık kullanılmaya başlanan kente karşı suç kavramının, kentsel suç kavramından farklılaştığı noktaları netleştirmek adına çalışmanın ilk aşamasında, kente karşı suç ile ilgili yabancı ve Türkçe literatürdeki kavramsallaştırmaları tartışmakta; ikinci aşamasında, TMMOB İzmir İl Koordinasyon Kurulu'nun (IKK) Ekim 2019'da çevrimiçi olarak yayınladığı 'İzmir Kent Suçları Haritası' üzerinden İzmir özelinde tespit edilen kente karşı suçlar değerlendirmektedir. Çalışmanın son aşamasında ise, kente karşı suçların ve bu suçlar kapsamındaki imar suçlarının önüne geçilebilmesi adına çeşitli planlama ilkeleri önermektedir.

\section{Yöntem}

Çalışmada, literatür taraması, kişisel gözlemler ve medya taramasından edinilen bulgular içerik analizi yöntemi kullanılarak dünyadaki ve İzmir özelindeki kente karşı suçlar tartışılmıştır. TMMOB İzmir İKK tarafından hazırlanıp Ekim 2019'da çevrimiçi olarak yayınlanan 'İzmir Kent Suçları Haritası' kapsaminda yer alan 72 proje ve uygulama incelenmiş ve kategorilendirilmiştir. Son olarak, özellikle imar suçları aracilığıyla işlenen kente karşı suçların önlenebilmesi için çeşitli planlama ilkeleri önerilmiştir. 


\section{Kent Suçu ya da Kente Karşı Suç}

Çalışmanın ilk aşamasında, yabancı literatürde kent suçunun doğrudan çevirisi olan 'urban crime' ya da 'urbanism and crime' anahtar kelimeleri ile araştırma yapıldığında, kentsel mekân, ırk ve suç arasındaki bağlantıları araştıran Chicago Okulu'na ait ya da bu okula referans veren çalışmalara rastlanmaktadır (Boggs, 1965). Ancak, 'white-collar crimes and urbanization', ya da 'corruption and building violations in urban planning' anahtar kelimeleri kullanıldığında, çalışma kapsamında araştırılan olgunun tanımına yakın çalışmalara ulaşılmaktadır (Boob ve Rao, 2012; Chiodelli, 2018; Green, 2005; Mekinc, 2013; Simkus, 1978; Tseng ve diğ., 2008). Türkçe literatürde ise 'kente karş1 işlenen suç', 'kente karşı suç' ya da 'imar suçu' anahtar kelimeleri kullanıldığında olgunun tanımına yakın çalışmalara ulaşılmaktadır (Geray, 2007; Giyik, 2018; Karasu, 2009; Karo, 2016; Keleş, 2007; Mengi, 2007; Şahin, 2006; Tekeli, 1994).

Kent suçu ya da kente karşı suç ile kentsel suç kavramları zaman zaman birbiriyle örtüşebilen eylemler içerseler de aralarında belirgin bir fark vardır: Kentsel suç, kentte işlenen kapkaç, gasp, cinayet gibi kriminal suçları ifade ederken; kente karşı suç, kentsel mekâna, çevreye, kentlilere ve kentli haklarına zarar veren karar ve uygulamaların tümünü ifade etmektedir.

Tekeli (1994), kente karşı suçu birey/insan hakları ve 'kentli hakları' üzerinden tariflemekte; kentli haklarının ve iyi kentin ne olduğu üzerinde durmaktadır. Bu durumda kente karşı suçu belirleyebilmek için, kentli haklarını tariflemek gerekmektedir. Avrupa Konseyi'nin 'Yerel ve Bölgesel Yönetimler Kongresi' tarafından 1992' de kabul edilen 'Avrupa Kentsel Şartı' kentli hakları konusunda bir başlangıç olarak kabul edilmektedir. Tekeli (1994) çalışmasında insan haklarını üç gruba ayırmakta; (1) temel haklar, (2) ekonomik, sosyal ve siyasal haklar, (3) dayanışma hakları (gelişme, barış, sağlıklı çevrede yaşam hakkı vb.); ve kentli haklarını yaşam kalitesi ve kamu yararı perspektifinden üçüncü grup haklar içerisinde tariflemektedir. Bu bağlamda, kentli haklarını yaşama geçirerek 'iyi bir kentsel yaşam oluşturmak' için devletin, özellikle yerel yönetimlerin, bireyleri toplumsallaştırmasına ve kentlilerin kentteki ortak (müşterek) alanlarını yeniden oluşturmasına ihtiyaç olduğunu ifade etmektedir (Tekeli, 1994).

Avrupa Konseyi, çağdaş yerel ve küresel kentsel sorunlara karşı 'Avrupa Kentsel Şartı'nın (1992) yeterli olmaması ve yeni sorunlara karşı ortak ilke ve kavramlar bütünü belirleme ihtiyacı sebebiyle 2008 yılında 'Avrupa Kentsel 
Şartı-2'yi yayınlamıştır. Bu manifesto ise temelde Avrupa değerleri esas alınarak, kamu politikalarında etik yönetişim, sürdürülebilir kalkınma ve ileri düzeyde dayanışma ilkeleri içermektedir (MO, 2008).

Kente karşı suç da kentli hakları perspektifinden tariflenmelidir. Mengi (2007), kente karşı suçu, "Kent olarak tanımlanan mekânlara ekonomik, sosyal, fiziksel ve kültürel yönlerden verilen zarar" şeklinde tariflemektedir. Kente karş1 işlenen suçların en büyük bölümünü ise 'imar kararlarına rağmen' ya da 'imar kararları aracılı̆̆ıyla' uygulanan 'imar suçları' oluşturmaktadır. İlk durumda imar suçları imar mevzuatına aykırı ve yasal anlamda suç sayılan eylemleri kapsarken; ikinci durumda hukuk kuralları içerisinde, ayrıcalıklı imar hakları, imar afları, yasalarda ek maddeler vb. araçlar kullanılarak işlenen suçları kapsamaktadır (Karasu, 2009; Mengi, 2007).

TMMOB İzmir İKK, Ekim 2019'da yayınladığı 'İzmir Kent Suçları Haritası' raporunda kent suçunu kısaca; "Toprak üzerinde yapılan her türlü insan yapımı faaliyetin; canlı yaşamı, ekolojik döngüler, kentsel yaşanabilirlik ve sağhlklı bir çeore üzerinde yarattığı veya yaratacağı tahribat ve bozulmanın ortaya çıkmasına neden olarak işlenen suç" olarak tanımlamıştır. Bu tanıma göre, hava kalitesinin, tarım ve mera alanlarının, su kaynaklarının, biyoçeşitliliğin, ekosistemlerin ve yaşam alanlarının zarar görmesine sebep olan; çeşitli çevre sorunlarına yol açan; ayrıcalıklı imar hakkı sağlayarak altyapı kapasitesinin üstünde yoğun yapılaşmaya neden olan parsel bazlı plan değişiklikleri ve projeler; kamu arazilerinin işgali ile rant sağlayıc ayrıcalıklar getirerek kentsel adaleti yok eden; kent siluetini bozan; tarihsel, doğal ve kültürel alanları tahrip eden; kent belleğine zarar veren; sosyal dokuyu olumsuz etkileyen; barınma, ulaşım gibi temel insan haklarını gasp eden; kamu zararı yaratan; kamu yararı içermeyen uygulamaların tümü kent suçları kapsamında değerlendirilmektedir (TMMOB İzmir İKK, 2019).

Kente karşı suç söz konusu olduğunda, kentin tümü, bir bölümü ya da o kentte yaşayanlar zarar görebilmektedir. Kente karşı suçlar, yasal olan ve olmayan eylemler olarak ikiye ayrılmaktadır. İlk tür suçlar, aynı zamanda hukuken de suç sayılan imar suçlarını kapsamaktadır. Bunlar için TCK'nın 181184. Maddeleri, 3194 sayılı İmar Kanunu 42. Maddesi vb. birçok yasal düzenleme bulunmasına rağmen, uygulamalara bakıldığında yeterli olmadığı görülmektedir. İkinci tür suçlar ise siyasi desteğe, toplumsal yozlaşmaya ve çkar ilişkilerine dayalı, hukuken doğru ama kamu yararı açısından yanlış eylemleri kapsamaktadır (Karasu, 2009; Keleş, 2007).

İkinci tur suçların çarpıcı bir temsiliyeti olarak, kentin sermaye gruplarına teslim edilişinin yakın dönem örneği, Özal ve Dalan döneminin İstanbul'u 
gösterilebilir. 1990'lı yıllarda ulusal ve uluslararası basının desteğini alan siyasetçiler, büyük sermaye gruplarının reklam panolarında yer almaya başlayan projeleri ile kentin pazarlanmasına olanak vermişlerdir (Öktem, 2011). Türkiye'de İstanbul ile başlayan ve sermayenin küreselleşmesi ile birlikte ülkenin diğer büyük kentlerine de sıçrayan bu süreç, günümüzde sadece kentsel alanları değil; 6360 sayılı Büyükşehir Kanunu ve 2634 sayılı Turizmi Teşvik Kanunu gibi yasal düzenlemelerle kırsal alanları da tehdit etmektedir. Özellikle, Kültür ve Turizm Bakanlığı gibi kurumların planlama yetkisi edinmesi ile başlayan süreç sonunda, nitelikli tarım arazileri ve kıyı alanları üzerinde yapılaşma baskısına sebep olan kararların arttı̆̆ı görülmektedir. Ayrıca bu tür planlama çalışmalarının parçacıl niteliği ve planlar arası hiyerarşinin kurulmaması da kente karşı suç kapsamında değerlendirilebilir.

Buna ek olarak, Türkiye'de birçok yapı iskansız ve yönetmeliklere aykırıdır. İstanbul ve Van depremleri ardından belirlenen kriterler ve çıkarılan yasalara rağmen kaçak yapılaşmanın önüne geçilememiştir (Çelik, 2007). Nitelikli konut sorunu ciddi boyuttadır ve son olarak 'İmar Barışı' (2018) adı altında çıkarılan imar affıyla birlikte bu sorun git gide daha da derinleşmektedir. İmar aflarının tümü, toplumsal adalet duygusunu zedelemesi, yapı güvenliğini hiçe sayması, doğal alanların devlet eliyle çitlenmesine zemin hazırlaması ve kamu zararı oluşturması sebepleriyle kente karşı suç kapsamında değerlendirilebilir.

Kente karşı suç, altyapısı hazır olmayan bir bölgeye, plansızca ve sadece kentsel rant uğruna getirilmiş olan trafik ve insan yoğunluğuna sebep olan tüm yatırımları ve bir kentteki adalet duygusunun zedelenmesine sebep olan tüm ayrıcalıklı uygulamaları kapsamaktadır. Kente karşı suç, kamusal kaynakları sıklıkla devlet eli ile çitlemekte ve çevreye/doğaya, insan yaşamına ve kamusal haklara zarar vermektedir. Boob ve Rao (2012), bir siyasal organ olan belediye meclisinin kentin nasıl gelişeceğini kontrol etmek için imar planı yapma yetkisine sahip olduğunun ve bu planlı gelişmenin en önemli amac1nın "Sağllklı kentsel mekanlar yaratarak dengeli bir büyüme să̆lamak" olması gerektiğinin altını çizmektedir. Bu bağlamda, plan kararları, sağlıklı kentsel çevreyi güçlendirmek için karmaşa, karışıklık, kalabalık ve trafik gibi unsurları önleyici ve azaltıcı, ayrıca imar uygulamalarında yaşanabilecek eşitsizlikleri ve mekânsal kullanım kararlarının çelişkilerini giderici yönde olmalıdır (Boob ve Rao, 2012).

Ancak ne yazık ki, Türkiye'de kente karşı suçların birçoğu belediye meclislerinin kabul ettiği imar planları ya da plan değişiklikleriyle olmaktadır. Bu yüzden, belediye meclisi gibi siyasal organların alacağı kararlarla kente karşı 
suç işleme riski her zaman vardır. Keleş (2007), kente karşı suç kavramının nesnel bir anlam kazanabilmesi için yasalarda net bir biçimde tanımlanması gerektiğinin altını çizmektedir.

Aksi halde, kente karşı duyulan sorumluluklar, ilgili kuruluşların siyasal ve etik sorumluluk ve önceliklerine göre esneyebilmektedir. Alınan kararlar sonucunda zarar görenin kent ya da kentin bir bölümü olması sebebiyle, bunlar adına davacı olabilecek aktörler, kentte yaşayanlar, kentte vergi verenler, kent yönetimini seçenler ve kentte yaşayanların kurmuş olduğu sivil toplum örgütleri, meslek odaları ve belediyeler olabilir. Bu sebepten, tüm kamu kuruluşları, sivil toplum örgütleri, meslek odaları ve kenttaşlar, başta kent içinde kalan sahipsiz mallara (müştereklere) olmak üzere, tüm kamusal alanlara ve kamu yararına karşı işlenebilecek bu suçları takip etmek ve davacı olmakla yükümlüdür (Keleş, 2007).

Kente karşı suçun nedenlerine bakıldığında karşılaşılan öncelikli unsur bireysel rant elde etme çabasıdır. Karasu (2009), bu durumun önüne geçmek için çeşitli öneriler sunmaktadır; kentsel rantın vergilendirilip kamuya aktarılması, katılımc planlama yaklaşımı, kentli haklarının net bir hukuki tanımının yapılması, iç göçün önlenmesi ve kentlilik bilincinin arttırılması için kentle bütünleştirici faaliyetler bu önerilerden bir kısmıdır (Karasu, 2009).

Kente karşı suçu işlemeye yönelik toplumsal eğilime dair özellikle az gelişmiş ve gelişmekte olan ülkelerde örnekler bulunmakta olup, Tseng ve arkadaşlarının (2008) çalışması dikkat çekicidir. Yazarlar Tayvan'da kente karşı suçların önüne geçilememesinin altı temel nedeni olduğundan bahseder: (1) inşaat işi yapan insanların yasalar ve yönetmelikler hakkında yeterli bilgiye sahip olmaması, (2) seçilmiş olan politik temsilciler ile yapılmakta olan lobi faaliyetleri, (3) var olan yasaların ve yönetmeliklerin bu tür ihlalleri yapanlar hakkında caydırıcı cezalara sahip olmaması, (4) yapılaşma ihlallerini tespit edebilecek teknik personel yetersizliği, (5) halkının büyük çoğunluğunun yapılaşma ihlallerinin, var olan haklarını genişleteceği ve yapılaşma koşullarının onların ihlallerine göre düzenleneceğine inanması, ve (6) kent yönetimi tarafından bu tür ihlallerin düzeltilmesi için açık kapı bırakılması (Tseng ve diğg., 2008). Türkiye için de büyük oranda geçerli olduğu söylenebilecek söz konusu saptamaların en çarpıcı yönü, kentsel politika, rant ekonomisi ve inşaat sektörü arasındaki bağlantıyı ortaya net bir şekilde koyuyor olmasıdır. Buna ek olarak, kente karşı suçları işleyen aktörlerin kimler olduğu ya da olabileceğine dair ipuçları vermesidir. 


\section{Kente Karşı Suçun Aktörleri}

Kente karşı suçu işleyen başlıca aktörlerin, merkezi ve yerel yönetimler, belediye meclisi vb. siyasal organlar, sivil toplum örgütleri, yatırımcılar ve yurttaşlar olduğu söylenebilir (Karasu, 2009). Bu sebepten, kente dair yapılacak her türlü suç ve usulsüzlük, birbiriyle bağlantılı kolektif ve organize bir eylemi teşkil etmektedir. Bu suçlar, sıklıkla kamuoyunda bilinen kişiler tarafından ve alenen işlenmektedir. Yabancı literatürde 1940'lı yıllardan itibaren 'beyaz yakalı suçları' içerisinde tanımlanan söz konusu aktörler, kentsel rantı kontrol edebilmek için yerel ya da merkezi devlet organları ile yasal ya da yasadışı bağlantıları bulunan, sıklıkla yüksek mertebeli, yerel dinamikleri etkileme gücüne ve medya kuruluşlarına sahip sermaye gruplarından oluşmaktadır (Nelken, 1994). Bu aktörler sıklıkla çevresel/ekolojik değerleri, etik gibi evrensel ilkeleri, bütüncül planlama ve sağlıklı kentsel gelişme gibi kentsel planlama mesleğinin omurgasını oluşturan konuları göz ardı etmektedirler ve küresel-kentsel stratejilerin izinde, politik iktisadi faaliyetleri çoğunlukla inşaat sektörüne odaklanmış Türkiye gibi gelişmekte olan ülkelerdeki kalkınma söylemlerinin de bir sonucu olarak, kente karşı suçlar, karşımıza bilinen suç tanımlarından farklı şekilde çıkmaktadır (Öktem, 2006).

Öte yandan, Penpecioğlu (2013), kente karşı suçlar kapsamındaki soylulaştırma projeleri ve alışveriş merkezleri gibi neoliberal kentleşme mekânlarını, Gramsci'nin 'hegemonya' ve Lefebvre' in 'mekânın üretimi' kavramları içerisinde değerlendirmektedir. Bu bağlamda, kente karşı suçları işleyen aktörler de 'rıza' yerine, 'zor' öğelerini kullanan 'hegemonik aktörler' olarak tariflenebilir.

İzmir özelinde, Özdilek, Folkart, İstinyePark gibi otel, rezidans ve AVM projelerinin müellifleri kentin siluetinin bozulmasına, kamu zararına ve altyapı eksikliklerine sebep olarak kente karşı suç işlerlerken; merkezi ve yerel yönetimlerle yakın ilişkiler geliştirerek kentin geleceğine yön verebilmektedirler. Yazık ki, bu aktörler söz konusu olduğunda, kesinleşmiş olan mahkeme kararlarının dahi uygulanmadığı durumlarla karşılaşılmakta ve mekânsal çatışmalara şahit olunmaktadır (Şekil 1-2). 


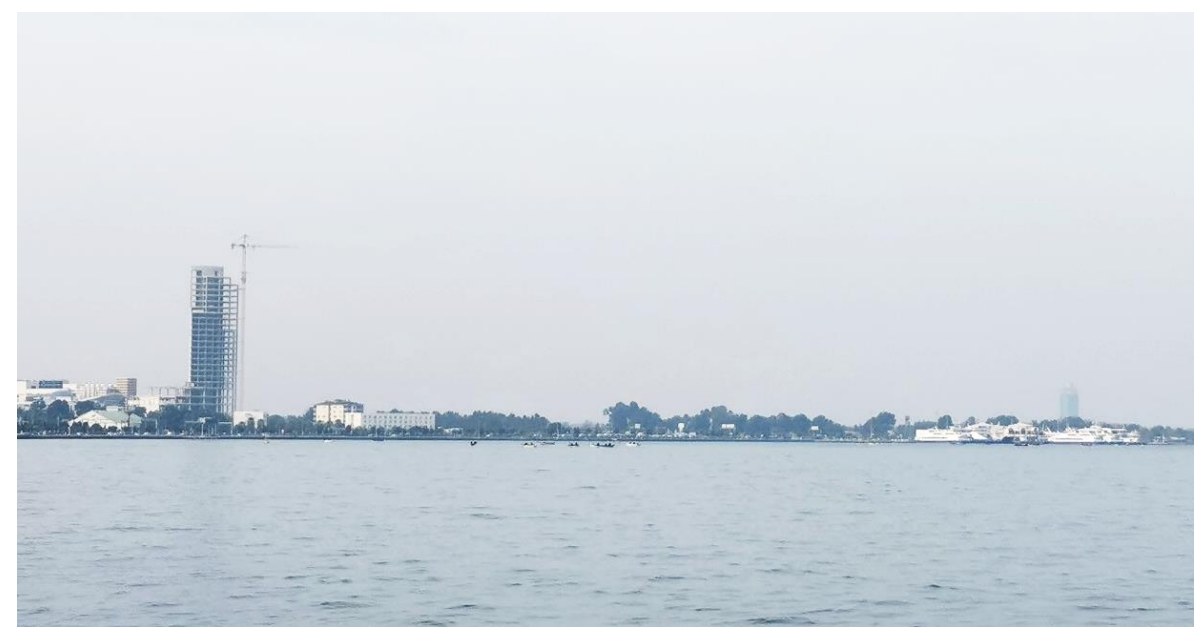

Şekil 1. Önde yürütme durdurma kararına rağmen inşaatı devam eden İstinyePark ve arkada onun öncülü olan Özdilek (Kişisel Arşiv, 2019)

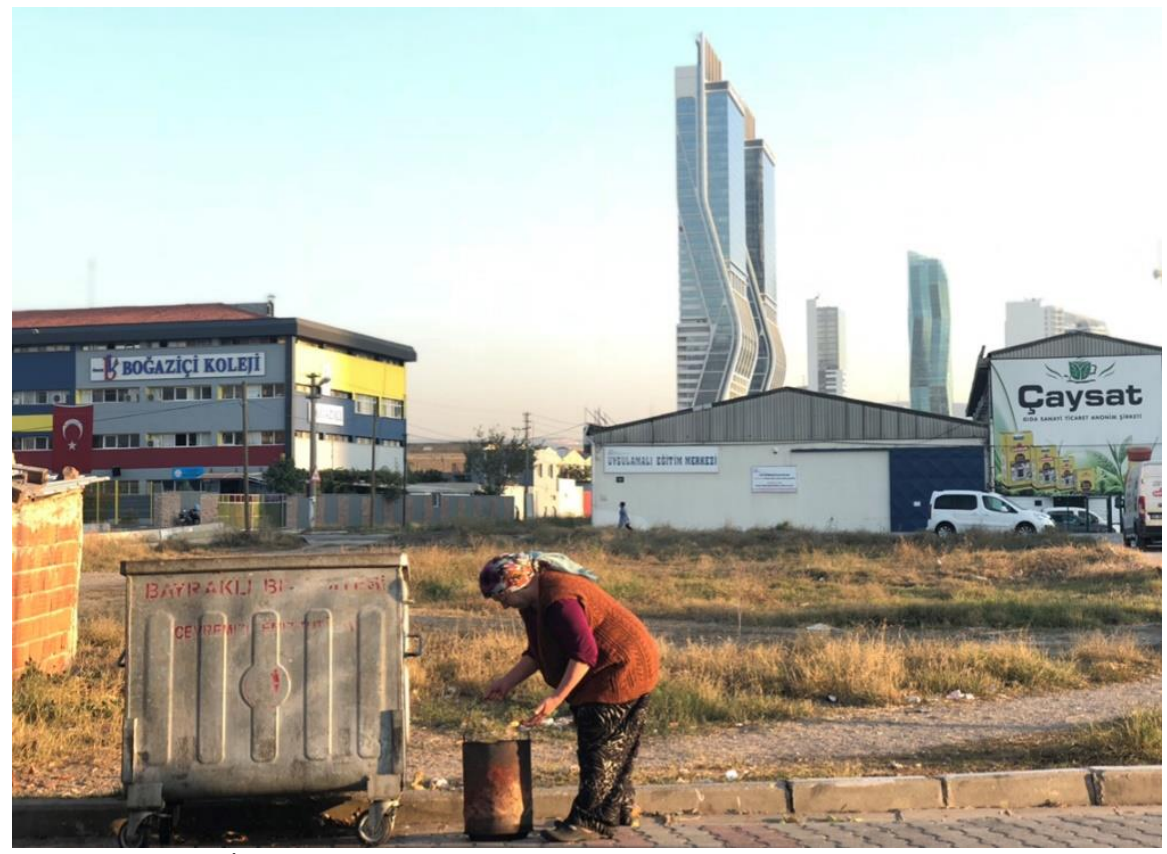

Şekil 2. İzmir'de mekânsal çatışma, Bayraklı (Şeyda Kaya Arşivi, 2018) 


\section{İzmir'de Kente Karşı İşlenen Suçlar}

Türkiye'de kente karşı suçların, İstanbul, Ankara ve İzmir gibi büyük kentlerde başı çektiği söylenebilir. İzmir'de planlanan rant projelerine dair hazırlanan bir raporda, plan revizyonlarında toplumun belirli kesimlerine rant aktarmaya yönelik spekülatif, parsel bazlı imar planı değişikliklerin yapıldığının ve İzmir üzerinde planlanan rant politikalarının en önemli aracının 'ayrıcalıklı imar hakları' veren imar planları olduğunun altı çizilmektedir (TMMOB İzmir İKK ve diğ., 2017).

Çalışma, halihazırda 72 kente karşı suçu kapsayan ‘İzmir Kent Suçları Haritası'nı incelemektedir. TMMOB'ye bağlı meslek odalarının dava süreçleri ve basın açıklamalarından yararlanılarak oluşturulan haritada kente karşı suç kapsamında değerlendirilen uygulamalar; (1) İmar planında yer almadan yapımına başlanmış, (2) Meslek odaları, yöre halkı, yerel yönetimler ve/veya çevre örgütlerinden en az biri tarafından itiraz edilmiş ya da iptali için yargıya başvurulmuş, (3) Kente vereceği zarar bilimsel raporlarla sabit olan, (4) İtirazlara ya da yargının aleyhte verdiği kararlara rağmen yapımına başlanan ya da devam eden, (4) Hava kalitesinin, tarım topraklarının, hayvancllı̆̆ın, su kaynaklarının, biyoçeşitliliğin ve ekosistemlerin zarar görmesine sebep olacak çeşitli çevre sorunlarına yol açan, (5) Ayrıcalıklı imar hakkı sağlayan, altyapı kapasitesinin üstünde yoğun yapılaşmaya neden olan, arazilerin rantını yükseltici ayrıcalıklar getiren, kentsel adaleti ortadan kaldıran, kent siluetini bozan, tarihsel, doğal ve kültürel anlamda korunması gerekli alanları olumsuz etkileyen, kent belleğinin yok olmasına neden olan, sosyal dokuyu olumsuz etkileyen, barınma, ulaşım, beslenme gibi temel hakları gasp eden ve kamu yararı içermeyen her türlü plan, proje ve uygulamalardır (TMMOB İzmir İKK, 2019).

İzmir'de işlenen kente karşı suçların kapsamı oldukça geniştir; doğal alanlar üzerindeki maden ve taş ocakları, maden arama ve genişletme sahaları, yerleşim yerine yakın yer seçen rüzgar elektrik santralleri, tarım alanlarını tehdit eden jeotermal enerji arama ve genişletme sahaları, yeraltı ve yerüstü sularının miktar ve kalitesine zarar verecek proje ve uygulamalar, kentteki heyelan alanlarının yerleşime açılması (ör. Uzundere Kentsel Dönüşüm Alanı), atık bertaraf tesisleri ve yer seçimleri, ayrıcalıklı imar haklarıyla ruhsat alıp projelendirilen gökdelenler ve yüksek katlı yapılar, meslek odalarının dava metinlerine konu olmuş AVM, rezidans ve diğer imar uygulamaları (ör. Üçkuyular pazar yeri / İstinyePark AVM, Bahçeşehir Çiçekli Köy Kampüsü, Özdilek AVM ve otel, Zorlu gökdelen projesi ve imar planı, Folkart Incity, 
Konak tünelleri, Basmane çukuru, iptal olan İnciraltı Expo planları, iptal olan Kültürpark revizyon projesi, Kültürpark eski İZFAŞ binalarının özel üniversiteye tahsis girişimi, doğal alanlar ve verimli tarım alanları üzerinde üniversite yerleşke projeleri, Aliağa ÖPA sanayi bölgesi, TRT binalarının bulunduğu arsa için yapılan imar planı değişikliği, Mahal Bomonti, Tariş planları, Çeşme Reisdere TOKİ planı), deniz yaşamını tehdit eden balık çiftlikleri, doğal yaşama zarar veren ve gerekliliği sorgulanan ulaşım altyapıları (ör. Çeşme Havalimanı, Karaburun'a yapılan yeni karayolu), kamusal alanda yapılan işgaller (ör. Mavibahçe, Folkart Narlıdere), Çandarlı Liman Projesi, doğal sit derecesi değişiklikleri, termik santraller, deniz ve kara yaşamın tehdit eden endüstriyel kazalar (ör. Aliağa-Foça Gemi Söküm Kazası ve petrol s1zıntısı), halk sağlığını, kent yaşamını ve doğal çevreyi tehdit eden yapılar (ör. Gaziemir Kurşun Fabrikası), gerekliliği sorgulanan ve doğal yaşam alanları ile tarımsal niteliği olan toprakları tehdit eden tüm imar uygulamaları (ör. kırsal alanlar üzerinde kurulmuş olan büyük yazlık siteler, Güzelbahçe Yelki go-kart pisti), çoğunlukla yoğun yeşil alan kullanımına sahip ve kent dışına taşınması söz konusu olursa kent parkı/kamusal alan olarak kullanılma potansiyeli olan askeri alanlar üzerindeki rant baskısı (ör. Bornova Doğanlar TOKİ), Konak tünelleri, hayata geçirilemeyen büyük ölçekli projeler (ör. İnciraltı EXPO, Körfez Geçişi), mera alanları üzerindeki dönüşüm baskısı vb. gibi geniş bir kapsama sahiptir. Ancak İzmir Kent Suçları Haritası'nda ilk etapta kente karşı suç olarak kategorilendirilen 72 uygulama ve projeye yer verilmiştir.

İzmir Kent Suçları haritasına işlenen suçlara oransal olarak bakıldığında, bu suçların \%36'sı kamu yararı olmayan ya da kamu zararına sebep olabilecek planlama uygulamaları, \%25'i kırsal alanlarda ortaya çıkan ve çevreyi tahrip etme riski bulunan proje ve uygulamalar; \%18'i imar planında yer almadan yapımına başlanmış uygulamalar; \%13'ü zararları bilimsel raporlar ile ispatlanmış uygulamalar; \%6'sı planlarda yer almasına rağmen itiraz edilmiş, iptali istenmiş ya da dava açılmış uygulamalar; ve \%2'si yapımına başlanmış ancak çeşitli sebeplerle yarım kalmış uygulamalar olarak tespit edilmiştir (Şekil 3-4). Merkez ilçelerdeki kente karşı suçlar bu kategorilere göre mekânsallaştırılmıştır (Şekil 5). 


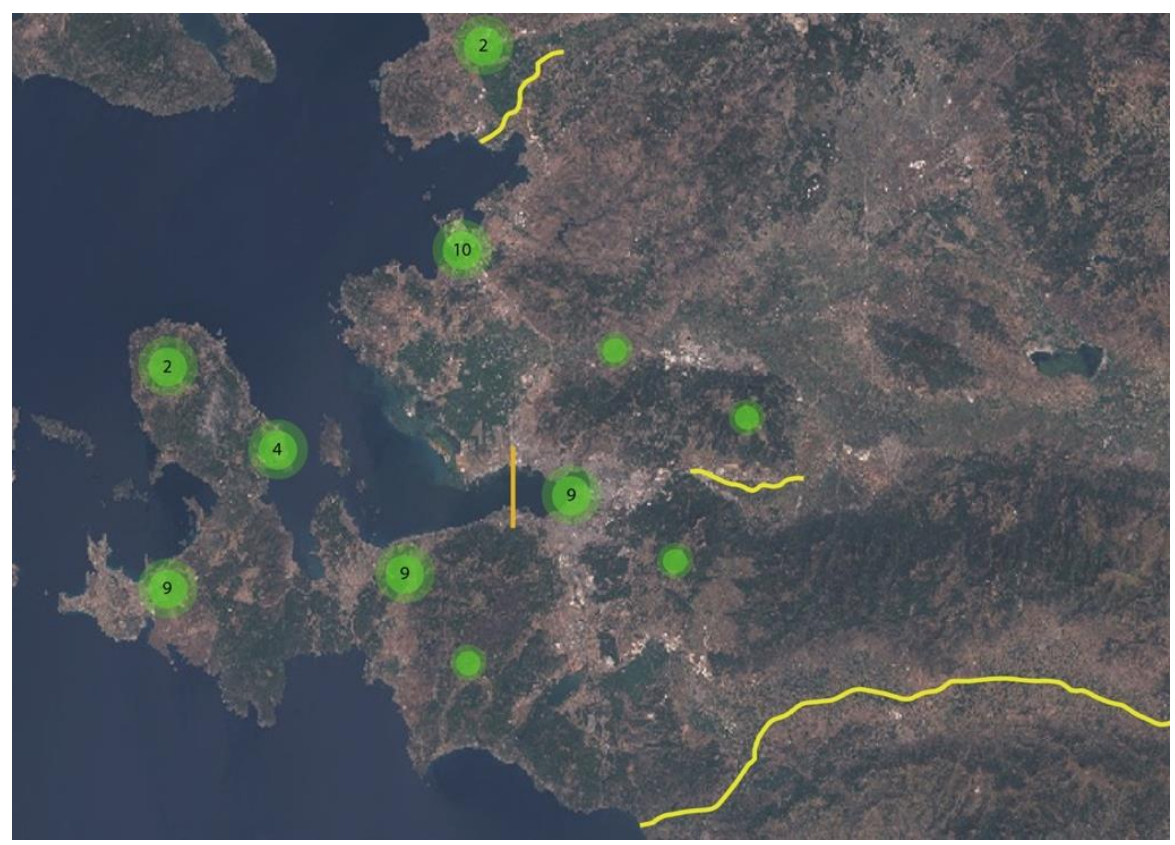

Şekil 3. İzmir'de Kente Karşı İşlenen Suçların Dağılımı (TMMOB İzmir İKK, 2019)

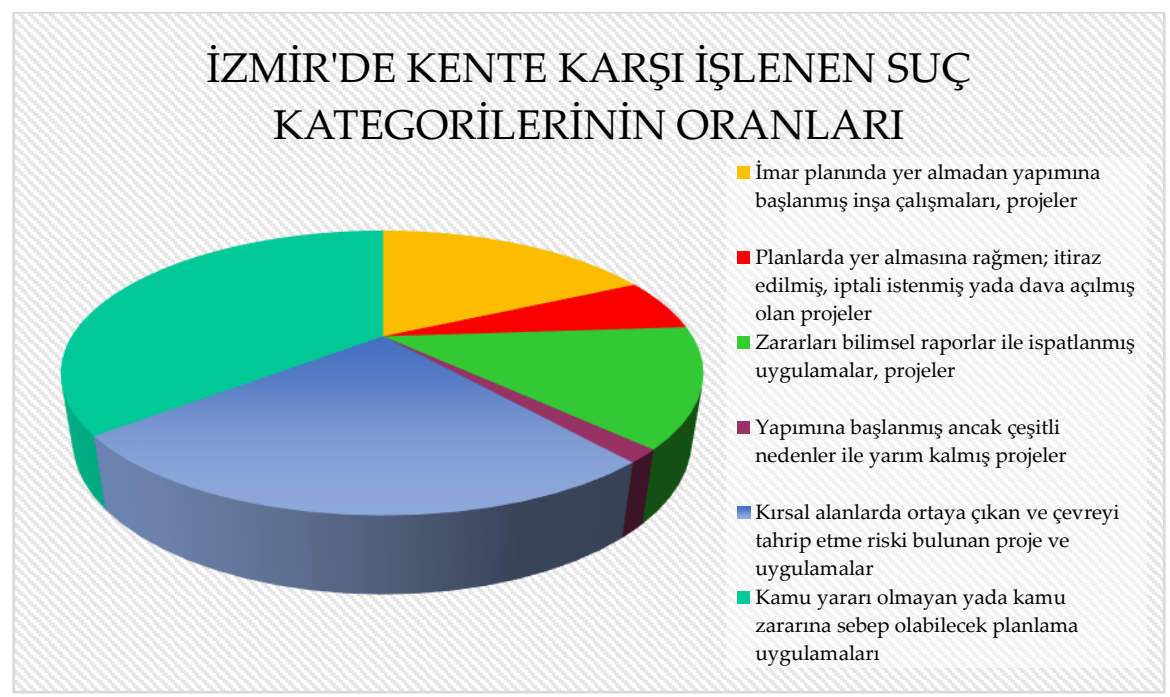

Şekil 4. İzmir Kente Karşı İşlenen Suç Kategorilerinin Oranları, 2019 


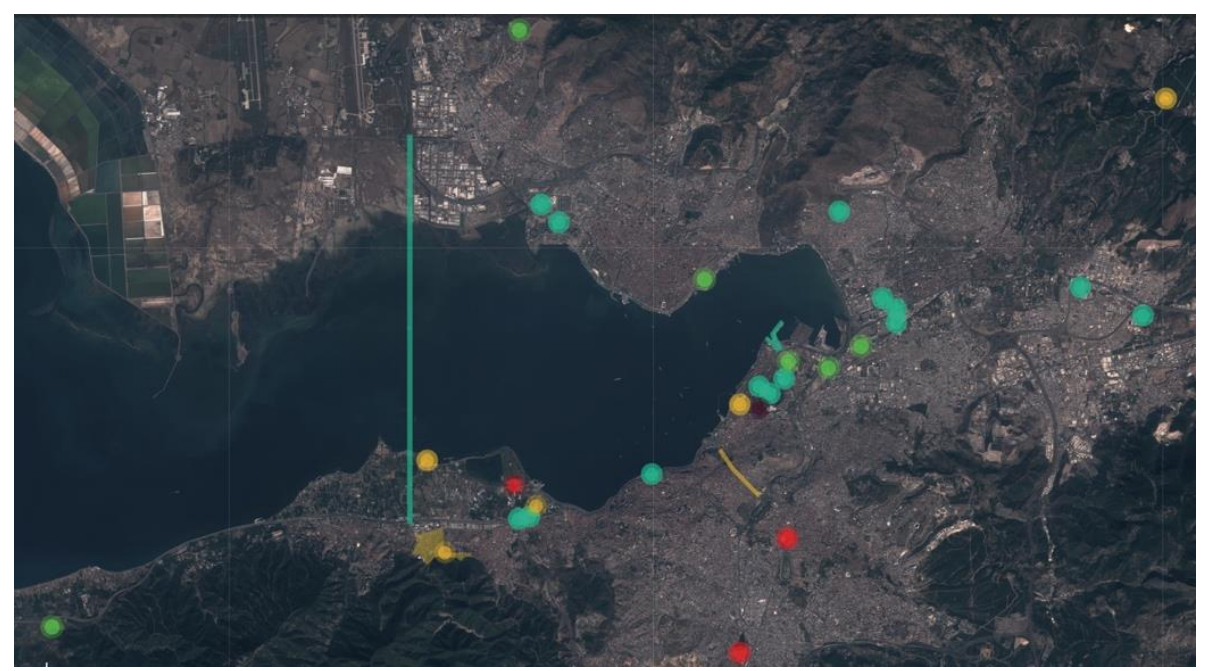

Şekil 5. İzmir Merkez İlçelerde Kente Karşı İşlenen Suçların Dağılımı, 2019

İzmir Kent Suçları Haritası güncellenmeye devam etmektedir. Kamuoyunu ve yerel basını meşgul eden "Zorlu Konak" gökdelen projesi gibi mevcut imar mevzuatında karışıklık varken ruhsat verilmiş, ancak meslek odaları tarafından açılan davalar ve kentlilerin tepkisiyle birlikte kente karşı suç kapsamında sayılan projeler de imar kararları aracılığıyla işlenen suçlar kategorisine dahil edilebilir. Bu tür projeler, planlamanın ve yerel yönetimlerin eksikliği ve gerektiği gibi kontrol edilemeyen 'hmax' uygulamasının bir sonucudur. Kentin tarihine, morfolojisine, altyapı eksikliklerine ve kent siluetine dikkat edilmeden yapılan söz konusu projeler, mekânsal eşitsizlik yaratmaları, kent belleğine zarar vermeleri ve kamu zararına sebep olmaları sebebiyle kente karşı suçtur.

Kente karşı suçların önüne geçilebilmesi için merkezi ve yerel yönetimlerin, üniversitelerin ilgili bölümlerinin, vatandaşların, meslek odalarının ve STK'ların koordinasyonlarını artırması ve ortak bir amaçla bir araya gelebilecekleri platformlar oluşturması gerekmektedir.

\section{Öneri Planlama İlkeleri}

Kente karşı suçların ve bu suçların büyük bir bölümünü oluşturan imar suçlarının önüne geçilebilmesi için çalışmada çeşitli planlama ilkeleri önerilmektedir;

- Kentin tarihsel gelişim süreci ve morfolojik gelişimi göz önüne alınarak, kent siluetinin tanımlanması ve bina yüksekliklerinin bu siluete uygun olarak belirlenmesi gerekmektedir 
- Kent alt bölgeleri ölçeğinde (ilçe, mahalle, semt vb.) kentsel tasarım rehberleri oluşturulmalıdır

- Kentte yapılacak altyapı yatırımı gerektiren projeler öncesinde altyapı eksiklikleri giderilmeli, ya da mevcut altyapının kapasitesi aşılmayacak şekilde nüfus artışı projelendirilmelidir

- Kent belleğini etkileyebilecek her türlü yatırım ve projede halkın katılımı esas alınmalı ve kent belleği azami ölçüde korunmalıdır

- Kente karşı suçların büyük bölümünü oluşturan imar suçlarının engellenebilmesi için kamu yararı esas alınmalı ve planlar arası hiyerarşi gözetilmelidir

- Kamu yararı içermeyen ya da kamuyu zarara uğratacak her türlü proje ve uygulamadan kaçınılmalıdır

- İmar planında bulunmadan yapımına başlanmış uygulama ve projeler, kentsel adaleti ve kentli hakların zedeleyen imar affı uygulamalarına son verilmelidir

- İmar planlarında bulunmasına rağmen meslek odaları, STK'lar ve vatandaşlar tarafından itiraz ve dava süreçlerine konu olmuş ve kente vereceği zarar bilimsel raporlarla kanıtlanmış uygulama ve projeler iptal edilmelidir

- Parçacıl plan revizyonları yerine stratejik etaplar halinde bütüncül ve katılımc planlama yaklaşımı gözetilmelidir

- 1/5000 Nazım İmar Planı ve 1/1000 Uygulama İmar Planı yapım süreçlerinde Büyükşehir Belediyesi, İlçe Belediyeleri ve belediye bünyesindeki birimler dahil kurumlar arası koordinasyon sağlanmalıdır

- Kent merkezini etkileyebilecek, özellikle merkez ilçelerdeki plan değişiklikleri öncesinde, Büyükşehir Belediyesi ve ilgili İlçe Belediyelerinin koordinasyonunda sivil toplum örgütlerinin ve ilgili meslek odalarının sürece dahil edileceği çalıştaylar düzenlenmelidir

- Kamu arazilerinin özelleştirilmesinin ve kentsel adaleti ve kentli haklarını zedeleyecek ayrıcalıklı imar haklarının önüne geçilmelidir

- Ortak (müşterek) arazilerin özelleştirilmesinin önüne geçilmeli, herhangi bir müdahalede bulunulacaksa da bu alanların kamuya kazandırılması sağlanmalıdır.

\section{Tartışma ve Sonuç}

İmar suçlarının tümünü ve çevre suçlarının bir bölümünü kapsayan kente karşı suçlar, kentli haklarını gasp etmektedir. Kırdan kente ve/veya kitlesel 
göç, planlar arası hiyerarşi eksikliği, esneklikten yoksun imar planları, rant kaygısıyla verilen ayrıcalıklı imar hakları, planlamada katılım eksikliği, kentlilik bilincinin olmayışı, yasal boşluklar vb. sebeplerle (Karasu, 2009) ortaya çıkan kente karşı suçları önlemek için, Türkiye'de imar mevzuatlarının ve kentleşme ile ilgili yasaların yeterliliğinin ve cezaların caydırıcılığının tartışıması gerekmektedir.

İzmir özelinde ise kente karşı suçları, gelişme ve kalkınma söylemleri ve sermayenin yeni mekân arayışları sürecinde İzmir'in potansiyel bir çekim noktasına dönüşmesi açılarından ele almak gerekmektedir. Sermaye hareketleri ve göçle gelen nüfus yapısı birçok yerde olduğu gibi İzmir'de de mekânsal eşitsizliğe sebep olmaktadır. Özkan ve arkadaşları (2019), İzmir inşaat sektörü özelinde sermaye hareketliliğini inceledikleri çalışmalarında, ulaşım yatırımları, konut, rezidans, AVM vb. inşaat yatırımları ile birlikte arsa, konut ve dükkân kiralarının artan oranda yükseldiğini görgül olarak ortaya koymuşlardır. Buna bağlı olarak, başta Çeşme, Urla, Bayraklı, Konak, Bornova ve Karşıyaka ilçelerinde yer alan rezidans, konut, AVM projelerinin üretimi önündeki engellerin ayrıcalıklı imar hakları ve parsel bazlı imar planı değişiklikleriyle kaldırılması sonucunda, İzmir kentinin sermaye açısından daha kârlı bir alan haline dönüştüğü değerlendirmesinde bulunmuşlardır (Özkan ve diğ., 2019). Gelişme ve kalkınma söylemlerinde elde edilen rantın büyüklüğünü çok katlı yapıların kentin dört bir yanını sarması ve çevre/doğa tahribatının göz ardı edilebilmesiyle paralel olarak düşünen merkezi yönetimin de süreçteki rolü yadsınmamalıdır.

İzmir Kent Suçları Haritası'na bakıldığında kamu zararına sebep olan ya da olabilecek plan uygulamalarının ve kırsal alanları tahrip etme riski bulunan proje ve uygulamaların oransal olarak yüksek olduğu görülmektedir. $\mathrm{Bu}$ bağlamda, kamu yararını odağına alan, katılımcı ve ekolojik duyarlı bir planlama yaklaşımının; imar suçları kapsamında yasal süreçlerin, hukuki olarak suç teşkil etmeyen uygulamalarda ise kamuoyu baskısının kente karşı suçları önleyici nitelikte olabileceği düşünülmektedir. Buna ek olarak, kente karşı suçların gerçek anlamda önüne geçilebilmesi ve bu suçları işleyenlere cayd1rıcı cezalar uygulanabilmesi için kente karşı suçların yasal bir çerçeveye oturtulması gerekmektedir.

\section{Teşekkür}

Yazarlar TMMOB İzmir İl Koordinasyon Kurulu, TMMOB Şehir Planc1ları Odası İzmir Şubesi ve şehir plancısı Şeyda KAYA'ya çalışmaya yapmış oldukları katkılardan dolayı teşekkür ederler. 


\section{Extended Abstract}

\section{Urban Crime or Crime Against the Urban: The Case of İzmir}

\author{
Dalya Hazar Kalonya \\ ORCID: 0000-0003-0075-0234
}

\author{
Zeynep Yildirım \\ ORCID: 0000-0002-0845-2816
}

The study investigates on what is expressed with the 'crime against the urban', how it is conceptualized in the literature and the crimes committed against İzmir. Although they may contain actions that overlap time to time, there are significant differences between the concept of 'crime against the urban' and the concept of 'urban crime', which have been widely used in Turkey in recent years. Urban crimes refer to criminal ones such as snatching, extortion and murder committed in the city; whereas the 'crime against the urban' refers to all decisions and practices that harm the urban space, environment, urban citizens and citizen rights. Major part of these crimes is the 'zoning crimes' that occurs despite the zoning decisions or through the zoning decisions. In the first case, the zoning crimes encompass actions that are contrary to the zoning legislation and deemed legally a crime; in the second case, crimes occur within the rules of law by privileged zoning rights, zoning amnesties, additional articles in the laws and similar tools. In this context, the study summarizes the debates about the crimes against the urban and discuss the crimes against İzmir through the 'Izmir Urban Crime Map' published online in 2019 by UCTEA (Union of Chambers of Turkish Engineers and Architects) İzmir Provincial Coordination Committee.

In recent years, economic development, unhealthy urbanization, unemployment and terrorism have become among the most important problems of Turkey (Karasu, 2009). The studies on the left and green political agenda examine these problems frequently referring to the concept of the 'crime against the urban'. However, the concept of 'crime against the urban' can be confusing with the concept of 'urban crime', which expresses the criminal crimes committed in the city in its direct English translation. 
The definition of 'crime against the urban', firstly declared by Murat Karayalçın, former Mayor of Ankara Metropolitan Municipality and Prof. İlhan Tekeli in 1970s and 1990s. Following the conceptualization of Tekeli (1994), the studies in the Turkish literature ave hfocused particularly on the 'zoning crimes'. The public awareness of the issue has increased through various websites and blog articles, press news and actions, papers, panels, urban crime maps (Istanbul, Bursa and Izmir), urban crime diaries and Istanbul urban struggles archive.

This study examines, categorizes and discusses the crimes against Izmir by using the content analysis of the findings from the literature review, personal observations, media analysis and the 72 projects and applications within the scope of 'Izmir Urban Crime Map' (2019). Finally, proposes various planning principles to prevent crimes against the urban, especially committed through the zoning crimes.

Tekeli (1994) describes 'crime against the urban' through individual and human rights and 'citizen rights'; and focuses on what a good city is. In this case, in order to determine the crime against the urban, it is necessary to describe the citizen rights. Tekeli (1994) divides human rights into three groups; (1) fundamental rights, (2) economic, social and political rights, (3) solidarity rights (development, peace, right to live in a healthy environment, etc.); and defines citizen rights within the third group of rights from the perspective of quality of life and public interest. In this context, it states that the state, especially local governments, needs to socialize individuals and re-create common areas of the city in order to 'create a good urban life' by realizing the citizen rights (Tekeli, 1994).

'Local and Regional Authorities Congress' in 1992 organized by the Council of Europe, is regarded as the beginning of the discussions on the citizen rights by 'European Urban Charter'. The Council of Europe published the 'European Urban Charter-2' in 2008 due to contemporary local and global urban problems and the need to determine the common principles and concepts. This manifesto, on the basis of European values, contains principles of ethical governance, sustainable development and advanced solidarity in public policies (MO, 2008).

Mengi (2007) describes the crime against the urban as "economic, social, physical and cultural damage to places defined as a city". The biggest part of the crimes against the city is 'zoning crimes', which are implemented despite 'zoning decisions' or 'through zoning decisions'. In the first case, zoning crimes 
include actions that are against the zoning legislation and are considered as legal crimes; In the second case, the rules of law, privileged zoning rights, zoning amnesties, and additional articles in the law become the tools of the crimes (Karasu, 2009; Mengi, 2007).

Specifically, it is crucial to deal with the crimes against the urban, development and development discourses and the transformation of İzmir into a potential attraction point during the search for a new space. Increasing investments and population structure that comes with migration cause spatial inequality in İzmir as well as in many other places. Özkan et al. (2019), examine the capital mobility in İzmir construction sector, transportation investments, housing, residence, shopping mall, etc. and reveal that land, housing and shop rents increased in parallel with the construction investments. Consequently, İzmir has become a more profitable area in terms of capital as a result of removing the obstacles in front of the production of residences and shopping malls located in Çeşme, Urla, Bayrakll, Konak, Bornova and Karşıyaka districts, with the help of the parcel-based development plans (Özkan et al., 2019).

The role of the central government in the process should not be ignored, considering the magnitude of the rent obtained in development discourses in parallel with the multi-storey buildings surrounding the city and the destruction of the environment / nature.

When we look at the Izmir Urban Crime Map, it is seen that the projects and applications that cause or may cause public damage and the risk of destroying the rural areas are proportionally higher. In this context, a participatory and ecologically sensitive planning approach focusing on the public interest; legal processes within the scope of zoning crimes and public pressure in the practices that do not constitute a crime as a legal act may prevent the crimes against the urban. In addition, crimes against the urban must be placed in a legal framework in order to efficiently prevent the crimes and to punish those who commit the crimes.

\section{Kaynakça/References}

Boggs, S. L. (1965). Urban crime patterns. American Sociological Review, 30 (6), 899-908.

Boob, T. N., \& Rao, Y. R. M. (2012). Violation of building Bye-Laws and development control rules: A case study, IOSR Journal of Mechanical and Civil Engineering 2 (4), 4859.

Chiodelli, F. (2019). The illicit side of urban development: Corruption and organised crime in the field of urban planning. Urban Studies, 56 (8), 1611-1627. 
Çelik, Ş. (2007). Türk inşaat sektörü ve inşaat sektörünün ülke ekonomisindeki etkilerinin araştırılması. Yüksek Lisans Tezi, Beykent Üniversitesi, İstanbul.

Geray, C. (2007). Güvenli kent ve kente karşı suçlar üzerine. TMMOB Mimarlar Odası Ankara Şubesi Bülten 55: Kent ve Suç, 6, 50-56.

Giyik, A. (2018). İmar kirliliğine neden olma suçu, TBB Dergisi, 134, 71-114.

Green, P. (2005). Disaster by design: corruption, construction and catastrophe. British Journal of Criminology, 45 (4), 528-546.

Karasu, M. A. (2009). Kente karşı suç: imar uygulamaları bağlamında kente karşı işlenen suçlar, Savaş Yayınevi, Ankara.

Karo, E. (2016). Kente karşı işlenen suçlar üzerine bir çözümleme: Bosna Hersek örneği. Doktora Tezi, İstanbul Üniversitesi, Sosyal Bilimler Enstitüsü, İstanbul.

Keleş, R. (2007). Kente Karşı Suç. TMMOB Mimarlar Odası Ankara Şubesi Bülten 55: Kent ve Suç, 6, 45-47.

Mekinc, J., Kociper, T., ve Dobovšek, B. (2013). The impact of corruption and organized crime on the development of sustainable tourism. Varstooslovje: Journal of Criminal Justice E Security, 15 (2).

Mengi, A. (2007). Kente karşı suç-imar suçu. TMMOB Mimarlar Odası Ankara Şubesi Bülten 55: Kent ve Suç, 6, 47-50.

MO (2008). Mimarlar Odası, Avrupa kentsel şartı-2: Yeni bir kentlilik için manifesto, 17.06.2020 tarihinde http://ceidizleme.org/ekutuphaneresim/dosya/125_1.pdf adresinden erişilmiştir.

Nelken, D. (Ed.). (1994). White-collar crime . Aldershot, England: Dartmouth. 355-392

Öktem, B. (2011). İstanbul'da neoliberal kentleşme modelinin sosyo-mekânsal izdüşümleri. İstanbul Üniversitesi Siyasal Bilgiler Fakültesi Dergisi, 44, 23-40.

Öktem, B. (2006). Neoliberal küreselleșmenin kentlerde inșası: AKP’nin küresel kent söylemi ve İstanbul'un kentsel dönüșüm projeleri. Planlama, 36, 53-65.

Özkan, S. P., Hazar, D., Özyiğit, M., Çelik, A., ve Aktaş, A. (2019). Sermayenin mekân arayışları: 2016-2018 yılları arası İzmir inşaat sektörü örneği, Ege Mimarlık (104), 5257.

Penpecioğlu, M. (2013). Büyük ölçekli kentsel projeler, mekânın üretimi ve neo-liberal hegemonya: İzmir örneğinde karşılaştırmalı bir araştırma. Megaron, 8 (2), 97-114.

Simkus, A. A. (1978). Residential segregation by occupation and race in ten urbanized areas, 1950-1970. American Sociological Review, 43, 81-93.

Tekeli, İ. (1994). Kente karşı işlenen suç mu? Yoksa kentlinin gasp edilen hakkı mı?, Bozkurt Güvenç'e Armağan, Kültür Bakanlığı Yayını, Ankara, 463-473.

TMMOB İzmir İKK, EGEÇEP ve Doğa Derneği, (2017). İzmir ve bölgemizde planlanan rant projeleri hakkında rapor, İzmir.

TMMOB İzmir İKK (2019). İzmir kent suçları haritası. 04.11.2019 tarihinde http://www.kentsuclari.org adresinden erişilmiştir. 
Tseng, P. K., Chiang, C. M., Hu, H. Y., ve Chen, C. Y. (2008). Categories of building violations and environmental externalities-empirical observation in Taiwan, Proceedings, 1-20. http://www.prres.net/Proceedings/..\%5CPapers\%5CTseng_Categories_Of_Building_Violations_And.pdf adresinden erişilmiştir. 